\title{
Immobilization of trypsin enzyme on silver nanoparticles
}

\author{
Sachin H. R., Prabhudev S. H., Ganesh Prasad D. N., A. H. Sneharani* \\ Department of Studies and Research in Biochemistry, Mangalore University, Jnana Kaveri Post Graduate Centre, Chikka \\ Aluvara, 571 232, Kodagu, Karnataka, India
}

(Received: April $2020 \quad$ Revised: May $2020 \quad$ Accepted: June 2020)

Corresponding author: A. H. Sneharani. Email: sneharaniah@gmail.com

\begin{abstract}
Introduction and Aim: Immobilization of enzyme on silver nanoparticles (AgNPs) is one way to improve their stability and activity and can be reused for large-scale applications. The present study was aimed to evaluate and characterize the trypsin enzyme immobilized on biogenically synthesized silver nanoparticles.

Materials and Methods: Immobilization of trypsin enzyme was optimized with time and varying concentration of silver nanoparticles, which were green synthesized using avocado seed extracts. The residual activity of trypsin enzyme after immobilization was estimated. The reusability and temperature stability of the immobilized enzyme were studied.

Results: The immobilized enzyme showed maximum activity of $1006.0 \mathrm{U}$ during the time duration of $18 \mathrm{hr}$ of incubation with AgNPs. Reusability of immobilized enzyme in avocado AgNPs was assessed under optimal conditions, the activity of immobilized enzyme was loss after 5 repeated cycles. The enzyme captured on AgNPs was released in the presence of anionic detergent. Temperature stability was assessed for immobilized enzyme on AgNPs and the immobilized enzyme was stable up to $55^{\circ} \mathrm{C}$ and later it loss their activity.

Conclusion: The study reports a feasible method of enzyme immobilization on biogenically synthesized silver nanoparticles. The enzyme immobilized on silver nanoparticles is mainly through non-covalent forces. Further studies are required to improve the reusability of enzyme.
\end{abstract}

Keywords: Silver nanoparticles; enzyme immobilization; trypsin; temperature stability; reusability; detergent.

\section{INTRODUCTION}

$\mathrm{E}$ nzymes are biocatalysts, involved in many biochemical reactions. They are universally present in plants and animals. Enzymes have extensive applications in health care, pharmaceuticals, leather, food and detergent industries (1-3). However, the use of enzyme in industrial applications are often set back due to some undesirable characteristics like, lack of shelf life, long-term operational stability at varying temperature, ionic strength and $\mathrm{pH}$ conditions, and recovery \& reusability. One strategy to overcome these problems is immobilization of enzymes on appropriate matrices.

Enzyme immobilization is used for enhancing the stability and reusability in aqueous media (4) and more recently in non-aqueous media $(5,6)$. Enzyme immobilization is advantageous when the intent of use of enzymes is in commercial and industrial set ups by offering high temperature stability and, hassle free downstream process and cost effective (7). In 1916 invertase enzyme was immobilized on a solid matrix, such as charcoal or an aluminum hydroxide (4) and demonstrated that activity of invertase enzyme was not hampered when it is adsorbed. This aspect led to the development of currently available enzyme immobilization techniques (8-10). The reaction catalysis of immobilised enzyme is maximum due to increase in binding capacity and thus becomes cost effective (11).

Free enzyme is relatively unstable when compared to immobilised counterpart. This is because the sturcture of the free enzyme determines the function and rate of reaction of the enzyme. In case of an immobilized enzyme the stability is determined by factors like nature of interaction with the matrix or carrier, stereochemistry of binding, and the microenvironment of the immobilized enzyme,the chemical and physical structure of the carrier, and the conditions under which the enzyme molecules were immobilized (12).

The choice of support matrix and designing the carrier are very important factors to be considered during enzyme immobilization. In recent years, nanostructured materials have taken their place as matrix for enzyme immobilization. Nanostructures based on silica, carbon nanotubes and metal nanoparticles silver, copper, zinc and gold nanoparticles are attractive matrixes for immobilization.

Nanoparticles as a matrix for enzyme immobilization Nanoparticles are very efficient support materials for enzyme immobilization, because of their high specific surface area, mass transfer resistance, and effective enzyme loading capacity (13-16). Moreover, the enzyme bound nanoparticles show Brownian movement, when dispersed in aqueous 
solutions showing that the enzymatic activities are comparatively better than that of the unbound enzyme (17). Various reviews on immobilization of enzymes on different types of nanoparticles (metal nanoparticles, metal oxide nanoparticles, magnetic nanoparticles, porous and polymeric nanoparticles etc.) have been reported earlier (18-20).

By using gold $(\mathrm{Au})$ and silver $(\mathrm{Ag})$ nanoparticles, enzymatic immobilization are studied using either as whole cells or isolated enzymes, which include lysozyme (21), glucose oxidase (22), and aminopeptidase (23), as well as alcohol dehydrogenase (24).

Lee et al., used amino-functionalized silica-coated magnetic nanoparticles to immobilize trypsin, they applied a pressure-assisted digestion for analysis, and more number of proteins was identified in comparison with the experiment with free trypsin (25).

In this study, optimization and characterization of trypsin enzyme immobilized on biogenically synthesized silver nanoparticles is carried. Further, the reusability temperature stability of bound enzyme is studied.

\section{MATERIALS AND METHODS}

Trypsin from bovine pancreas, silver nitrate (AgNO3) and sodium dodecyl sulphate (SDS) was purchased from Sigma Aldrich chemicals. All other reagents were of analytical grade.

\section{Methods}

\section{Synthesis of silver nanoparticles}

Silver nanoparticles are synthesized as described in Sneharani et al., (26).

\section{Immobilization of trypsin enzyme}

\section{Time dependent immobilization}

The immobilization of trypsin enzyme on AgNPs for different time $(0,1,5,10,15,18$, and $21 \mathrm{hr})$ was carried out by keeping $100 \mu \mathrm{L}$ of trypsin solution $(1 \mu \mathrm{g} / \mu \mathrm{L})$ in $1.5 \mathrm{~mL}$ tube containing $100 \mu \mathrm{L}$ of concentrated AgNPs. The volume was made up to $500 \mu \mathrm{L}$ using distilled water, mix thoroughly and kept on Rotospin at constant speed $25 \mathrm{rpm}$ at $6-8^{\circ} \mathrm{C}$.

\section{Optimization of different concentration of trypsin on immobilization}

Varying concentration of trypsin (100-500 $\mu \mathrm{g}$ ) were added to tube containing AgNPs and kept for incubation for $18 \mathrm{hr}$.After incubation the reaction mixture was centrifuged at $14,500 \mathrm{rpm}$ for $30 \mathrm{~min}$. The supernatant contains unbound enzyme and the pellets are AgNPs bound with enzyme. To the pellet $50 \mu \mathrm{L}$ distilled water is added and used as the source of immobilized enzyme.

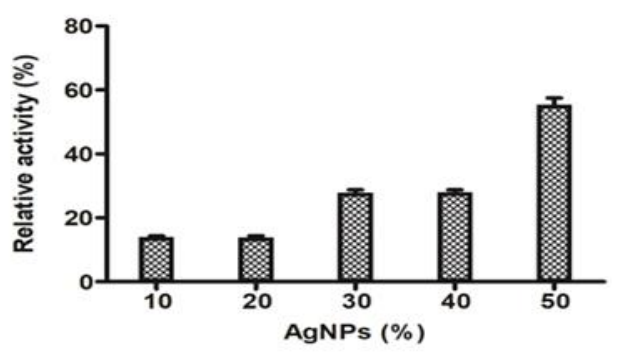

Fig. 1: Effect of different concentration of AgNPs on enzyme immobilization

\section{Enzyme assays for trypsin}

The activity of free and immobilized trypsin was detected by the method of Erlanger et al., (1961) with slight modification. Proteolytic activity was examined by measuring the hydrolysis of peptidylpNAs (BAPNA). The rate of enzymatic hydrolysis of peptidyl-pNAs substrates was measured using a colorimeter at $450 \mathrm{~nm}$.

\section{Reusability of immobilized enzyme}

The reusability of the immobilized trypsin was evaluated for BAPNA hydrolysis at $37^{\circ} \mathrm{C}$. After each cycle of enzyme assay, the immobilized trypsin was collected by centrifugation, washed several times with distilled water and used to check the enzyme activity. The immobilized trypsin on first use is assigned to have a relative activity of $100 \%$.

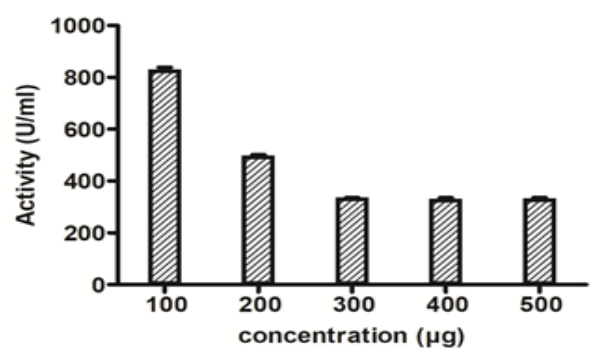

Fig. 2: The activity of immobilized enzyme in presence of different concentration of trypsin

\section{Thermal stability of immobilized enzyme}

The thermal stability of trypsin in its free and immobilized states was evaluated by measuring the residual activity at different temperature in tris- $\mathrm{HCl}$ buffer (pH $8.250 \mathrm{mmol} / \mathrm{L}$, BAPNA). The residual trypsin activity was measured at varying periods of temperature $\left(4^{\circ} \mathrm{C}, 25^{\circ} \mathrm{C}, 37^{\circ} \mathrm{C}, 55^{\circ} \mathrm{C}, 65^{\circ} \mathrm{C}\right.$, and $75^{\circ} \mathrm{C}$ ). The free and immobilized trypsin without incubation was assigned a relative activity of $100 \%$.

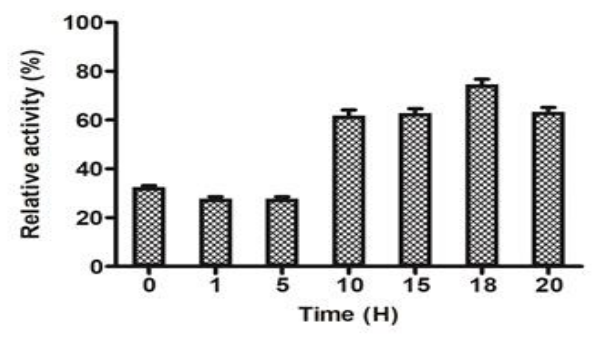

Fig. 3: Effect of different time interval for enzyme immobilization 
Effect of detergent on free and immobilized enzyme Enzyme activity of unbound and immobilized enzyme in presence of anionic detergent (sodium dodecyl sulphate) was checked by adding varying concentration of SDS (0.1-0.5 \%). The enzyme activity is measured at $450 \mathrm{~nm}$ in colorimeter.

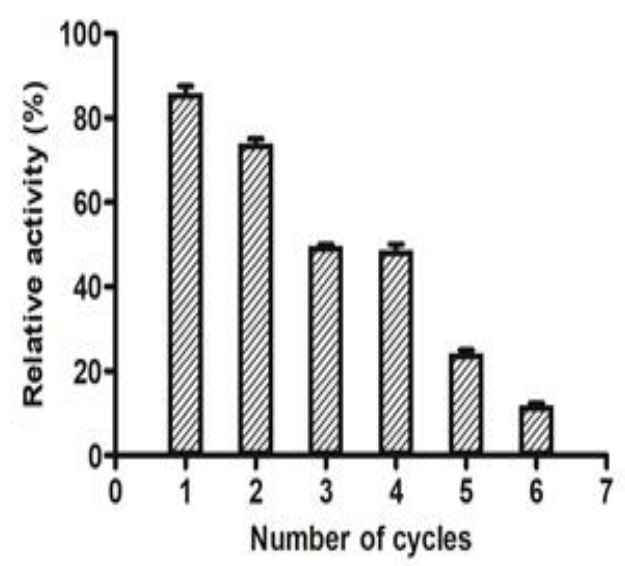

Fig. 4: Reusability of immobilized enzyme

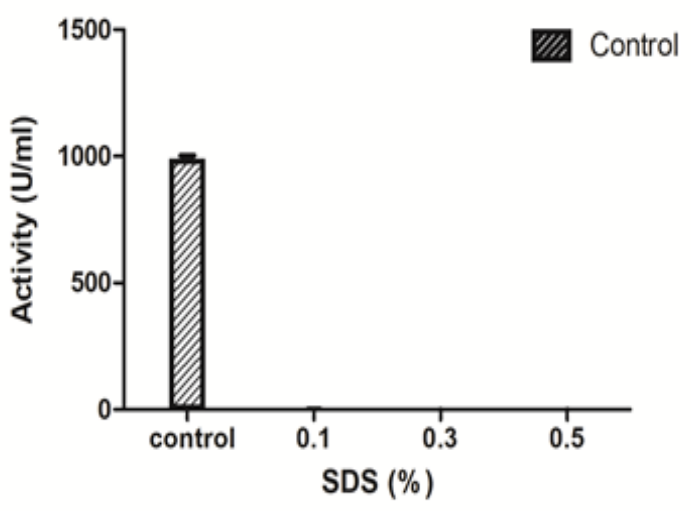

Fig. 5: Effect of different concentration of detergent on activity of enzyme

\section{RESULTS AND DISCUSSION}

\section{Optimization of trypsin immobilization on silver nanoparticles}

Fig. 1 shows the optimization of percent AgNPs for immobilizing the trypsin enzyme. Percent concentration ranging from 10 to $50(\mathrm{w} / \mathrm{v})$ was incubated with trypsin. At the end of incubation period, the AgNPs bound to enzyme were collected and the activity of enzyme was checked. A linear increase in the activity of enzyme was observed with increase in concentration of AgNPs from 10 to $50 \%$. This is due to the increase in the available surface area for the attachment of enzyme on AgNPs. Likewise, to optimise the trypsin concentration for optimal binding varying the concentration of trypsin $(100$ to $500 \mu \mathrm{g})$ was incubated with $50 \%$ concentration of AgNPs. Fig. 2 shows the activity of immobilized enzyme in presence of different concentration of trypsin on AgNPs. At $100 \mu \mathrm{g}$ of trypsin, maximum activity of enzyme was seen. At this concentration all the available surface on AgNPs is occupied with trypsin.

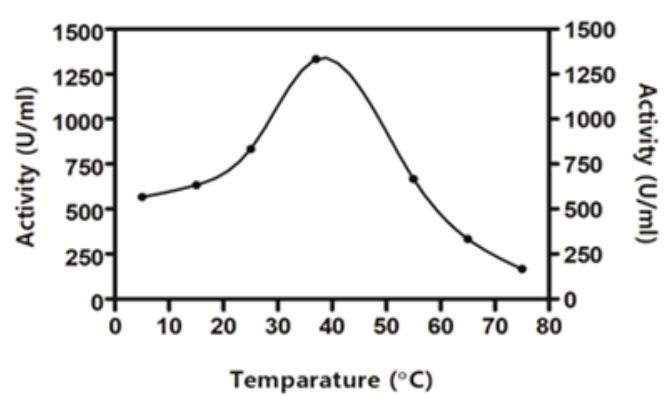

Fig. 6: Effect of temperature on activity of immobilized enzyme

\section{Optimization of incubation time}

Trypsin enzyme $(100 \mu \mathrm{g})$ was incubated with AgNPs $(50 \%)$ at different time interval at optimal conditions. The immobilization of trypsin enzyme on AgNPs varied with time. At 5th hour of incubation binding of enzyme was initiated which was confirmed by trypsin activity. At 18th hour of incubation, maximum enzyme activity was observed. At 21 hour of incubation, the enzyme activity started to decrease as represented in Fig. 3.

\section{Reusability of immobilized enzyme}

The reusability of the immobilized trypsin was evaluated by using the same batch of immobilized trypsin by repeating the activity assays. From fig. 4 it can be inferred that up to cycle of repetitive use of enzyme the activity of the enzyme was retained although the activity of the immobilized trypsin decreased as the number of reuse cycles increased. At the end of 5thcycle of use of same immobilized trypsin enzyme activity $70.32 \%$ retained. This shows the potential of immobilization of trypsin enzyme on AgNPs.

\section{Effect of detergent on immobilization}

The check the nature of binding of enzyme on AgNPs, the immobilised enzyme and the unbound enzyme were treated with SDS. Figure 5 shows the effect of different concentration of detergent on enzyme activity. With treatment of detergent, both the unbound and bound enzyme lost the activity showing that there is loss in the structure of enzyme in presence of detergent. Along with experimental samples, control without the addition of detergent was tested for enzyme activity. This is represented as 100\% activity in Fig. 5.

\section{Effect of temperature}

Due to sensitivity at higher temperatures, enzymes are heat labile and immobilizing enzymes often overcome this. The thermal stability of the immobilized trypsin was measured in comparison with that of free trypsin. Fig. 6 shows the result of thermal stability of the trypsin immobilized on AgNPs. The activity of trypsin immobilized on AgNPs was comparatively stable when compared with unbound enzyme at different temperature. The unbound trypsin lost almost all of its activity at $60^{\circ} \mathrm{C}$ 
after 1 hour of incubation, whereas the immobilized trypsin retained more than $25 \%$ of its residual activity at the end of $1 \mathrm{~h}$ of incubation. The enzymes immobilized on AgNPs are more stable than the unbound enzyme. The thermal stability of the immobilized trypsin is enhanced at high temperature. This is due to the protection of any conformational denaturation of the enzyme at higher temperatures, making it more heat-resistant than in unbound form.

\section{CONCLUSION}

Using the immobilization technique, the enzyme activity and stability can be enhanced. In this study, metal nanoparticles were used to immobilize the enzyme. Small size and large surface area of the nanoparticles favours enzyme immobilization and stabilization. In this study, we observed increase in the stability and activity of enzymes increases when immobilized on such materials.

\section{CONFLICT OF INTEREST: None. \\ REFERENCES}

1. Gomes-Ruffi, C. R., Cunha, R. H., Almeida, E. L., Chang, Y. K., Steel, C. J. Effect of the emulsifier sodium stearoyllactylate and of the enzyme maltogenic amylase on the quality of pan bread during storage. Lwt-Food SciTechnol. 2012; 49: 96-101.

2. Jaros, D., Rohm, H. Enzymes exogenous to milk in dairy technology transglutaminase: Encyclopaedia of dairy sciences, Academic Press. 2011.

3. Tonini, D., Astrup, T. Life-cycle assessment of a waste refinery process for enzymatic treatment of municipal solid waste. Waste Manag. 2012; 32: 165-176.

4. Nelson, J. M., Griffin, E. G. Adsorption of Invertase. J Am ChemSoc. 1916; 38: 1109-1115.

5. Wang, Q., Yang, Z., Wang, L., Ma, M., Xu, B. Molecular hydrogel-immobilized enzymes exhibit super activity and high stability in organic solvents. Chem Commun. 2007; 10: 1032-1034.

6. Iyer, P. V., Ananthanarayan, L. Enzyme stability and stabilization - aqueous and non-aqueous environment. ProcessBiochem. 2008; 43(10): 1019-1032.

7. Mateo, C., Palomo, J. M., Fernandez-Lorente, G., Guisan, J. M., Fernandez-Lafuente, R. Improvement of enzyme activity, stability and selectivity via immobilization techniques. Enz Microb Technol. 2007; 40(6): 1451-1463. DOI: 10.1016/j.enzmictec.2007.01.018.

8. Massolini, G., Calleri, E. Immobilized trypsin systems coupled on-line to separation methods: recent developments and analytical applications. J Sep Sci. 2005; 28: 7-21.

9. Guzik, U., Hupert-Kocurek, K., Wojcieszy^̊,,ska, D. Immobilization as a strategy for improving enzyme properties-application to oxidoreductases. Molecules 2014; 19: 8995-9018.

10. Rodrigues, R. C., Ortiz, C., Berenguer-Murcia, Á., Torres, R., Fernández-Lafuente, R. Modifying enzyme activity and selectivity by immobilization. ChemSoc Rev. 2013; 42: 6290-6307.

11. Secundo, F. Conformational changes of enzymes upon immobilisation. ChemSoc Rev. 2013; 42: 6250-6261.

12. Liese, A., Hilterhaus, L. Evaluation of immobilized enzymes for industrial applications. ChemSoc Rev. 2013; 42: 6236-6249.

13. Feng, W., Ji, P. Enzymes immobilized on carbon nanotubes. BiotechnolAdv. 2011; 29: 889-895.
14. Gupta, M. N., Kaloti, M., Kapoor, M., Solanki, K. Nanomaterials as matrices for enzyme immobilization. Artif Cells Blood SubstitImmobilBiotechnol. 2011; 39: 98-109.

15. Ansari, S. A., Husain, Q. Potential applications of enzymes immobilized on/in nano materials: A review. Biotechnologv. 2012; 30: 512-523.

16. Verma, M. L., Barrow, C. J., Puri, M. Nanobiotechnology as a novel paradigm for enzyme immobilisation and stabilisation with potential applications in biodiesel production. ApplMicrobiolBiotechnol. 2013; 97: 23-39.

17. Gupta, M. N., Kaloti, M., Kapoor, M., Solanki, K. Nanomaterials as matrices for enzyme immobilization. Artif Cells Blood SubstitImmobilBiotechnol. 2011; 39: 98-109.

18. Ansari, S. A., Husain, Q. Potential applications of enzymes immobilized on/in nano materials: A review. BiotechnolAdv. 2012; 30: 512-523.

19. Cipolatti, E. P., Silva, M. J., Klein, M., Feddern, V., Feltes, M.M.C., Oliveira, J. V., et al., Current status and trends in enzymatic nanoimmobilization. J MolCatal B: Enzym. 2014; 99: 56-67.

20. Min, K., Yoo, Y. J. Recent progress in nanobiocatalysis for enzyme immobilization and its application. Biotechnology and Bioprocess Engineering. 2014; 19: 553-567.

21. Vertegel, A. A., Siegel, R. W., Dordick, J. S. Silica nanoparticle size influences the structure and enzymatic activity of adsorbed lysozyme. Langmuir. 2004; 20: 68006807.

22. Lan, D., Li, B., Zhang, Z. Chemiluminescence flow biosensor for glucose based on gold nanoparticle-enhanced activities of glucose oxidase and horseradish peroxidase. BiosensBioelectron. 2008; 24: 940-944.

23. Wu, C. L., Chen, Y. P., Yang, J. C., Lo, H. F., Lin, L. L. Characterization of lysine-tagged Bacillus stearothermo philusleucine aminopeptidase II immobilized onto carboxylated gold nanoparticles. J MolCatal B: Enzym. 2008; 54: 83-89.

24. Keighron, J. D., Keating, C. D. Enzyme: nanoparticle bioconjugates with two sequential enzymes: stoichiometry and activity of malate dehydrogenase and citrate synthase on Au nanoparticles. Langmuir. 2010; 26: 18992-19000.

25. Lee, B., Lopez-Ferrer, D., Kim, B. C., Na, H. B., Park, Y. II., Weitz, K. K., et al., Rapid and efficient protein digestion using trypsin-coated magnetic nanoparticles under pressure cycles. Proteomics. 2011; 11: 309-318.

26. Sneharani, A. H., Prabhudev, S. H., Sachin, H. R. Effect of phytochemicals on optical absorption spectra during biogenic synthesis of self-assembled silver nanoparticles and studies relevant to food applications. Spectroscopy Letters. 2019; 52(7): 413-422. 